LetTer From the PUblisher

\section{No longer free for all}

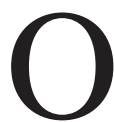

n Mar. 29, 1995, the Canadian Medical Association became the first national medical association in the world with a presence on the Internet, and CMAJ has been with us from the start of that journey. Since then, we have been committed to providing readers with free, full-text access to all of our content. Unfortunately, recent and ongoing economic realities dictate that we will no longer be able to do so.

Beginning January 2010, non-members of the CMA will have to pay for access to some of the content on cmaj.ca. The resulting revenue from subscriptions should help to mitigate our current deficit.

As CMAJ Editor-in-Chief Dr. Paul Hébert explains in his $\approx$ accompanying letter, this decision was far from easy.

The harsh economic reality is that CMAJ, like many others in the publishing industry, has experienced a considerable decline in advertising revenue over the past two years. This loss necessitated an extensive examination of other business models to adequately address today's economic challenges. Controlled access will allow us to sell electronic sub- scriptions and further diversify our revenue streams. We must make this move for the ongoing health of CMAJ.

Members of the CMA will be able to access cmaj.ca through the CMA's website using a cma.ca user name and password. Readers who wish to subscribe, need help with access through cma.ca or want more information should contact the CMA's Member Service Centre at cmamsc@cma.ca or $888855-2555$.

The steps we have taken are driven by the firm commitment of the CMA and its Board of Directors to continue publishing Canada's pre-eminent medical journal. ${ }^{1}$

\section{Glenda Proctor MSc}

Director and Publisher

CMA Publications

\section{REFERENCE}

1. Golbey M, Drew B, Cloutier P-E. Letter from the Canadian Medical Association: The health of CMAJ. CMAJ 2009;181:124. 